\title{
Alcohol use in early adolescence: findings from a survey among middle school students in Italy
}

\author{
Rossella Zucco ${ }^{1}$, Franco Montesano ${ }^{2}$, Stefania Esposito ${ }^{2}$, Aida Bianco ${ }^{1}$ and Carmelo G A Nobile ${ }^{3,4}$
}

BACKGROUND: The aims of this study were to measure the extent of alcohol use among a sample of early adolescents and to provide information on the factors influencing the consumption.

METHODS: Data were collected via self-administered anonymous questionnaires from 1,520 middle school students (mean age of 13.1 years (range 12-15 years)), who were recruited from a random sample of public schools in Calabria Region, Italy.

RESULTS: A total of 1,032 participants completed the survey for a response rate of $68 \%$. Nearly $70 \%$ of the respondents had drunk at least once during their lifetime, and $16.7 \%$ reported consuming alcohol during 30 days before the survey. Multivariate analysis showed that the factors associated with the consumption of alcohol were being male (odds ratio (OR) $0.58,95 \%$ confidence interval (Cl) $0.41-0.80$ ), being older (OR $1.88,95 \% \mathrm{Cl} 1.37-2.56)$, living in an urban area (OR $0.29,95 \% \mathrm{Cl}$ $0.21-0.40$ ), reporting a sad self-perceived mood (OR 2.76, 95\% Cl 1.87-4.48), reporting parental drinking habits (OR 7.11, 95\% Cl 5.02-10.08), and not considering alcohol use as an unhealthy behavior (OR 2.43, 95\% Cl 1.11-5.31).

CONCLUSION: Alcohol use among early adolescents is widespread. Multicomponent interventions are required in order to reduce the average levels of alcohol drinking among early adolescents.

E arly adolescence (occurring between the ages of 10 and 15 years), is characterized by rapid physical, cognitive, and social transformations (1), during which youth often get engage in risky behaviors, such as alcohol use $(2,3)$.

In the United States, results from the 2013 National Youth Risk Behavior Survey (YRBS) indicated that $66.2 \%$ of $13-16$ year-old adolescents consumed at least one drink of alcohol on at least 1 day during their lifetime, and $18.6 \%$ had drunk alcohol for the first time before 13 years of age (4). Moreover, data reported from the European School Survey Project on Alcohol and Other Drugs (ESPAD) showed that at least 70\% of the interviewed students have drunk alcohol at least once during their lifetime, with an average of $87 \%$ in the 2011 survey (5). Alcohol use in 12 months and 30 days preceding the survey was $79 \%$ and $57 \%$, respectively, and the rates of "binge drinking", defined as five or more drinks on the same occasion $(5,6)$, were $43 \%$ for boys and $38 \%$ for girls. Alcohol use has also grown among Italian adolescents. According to the Italian National Institute of Statistics (ISTAT), in 2014, about $10 \%$ of 11-15-year-old Italian adolescents were current drinkers (7). These data are extremely worrying, because early adolescent brain, especially the hippocampus, may be particularly vulnerable to the effects of alcohol (8), thus predisposing the young drinker to alcohol, mental health, and neuro-cognitive problems, that can persist into adulthood $(8,9)$. Young people who start drinking before the age of 15 years are reported to be four times more likely to meet the criteria for alcohol-dependence at some point in their lives, and early alcohol use is associated not only with more regular and higher levels of alcohol use and dependence in adulthood, but also with an increased risk of other substance use in later adolescence $(10,11)$.

However, if drinking habits are now well documented in high school students $(6,12)$, few studies have focused on alcohol use in children and middle school students $(13,14)$. Therefore, the primary aim of this study was to measure the extent of alcohol use among a sample of middle school students in Calabria region, Italy, whereas the secondary aims were to evaluate knowledge, attitudes, and behavior regarding alcohol consumption, and to evaluate the potential factors influencing alcohol use.

\section{METHODS}

The study was conducted from October 2014 to May 2015 on a sample of 1,520 eligible students. Data were collected as part of a multimodal intervention for the primary prevention of risky health behaviors among middle school students called "Luoghi di Prevenzione" (LdP), that is a part of the National Prevention Plan of the Italian Ministry of Health (15).

A total of 24 public middle schools, randomly selected from a total of 50 middle schools in the geographic area of Catanzaro, in South Italy, was involved in the study. Before starting data collection, a meeting with the head of each selected school was arranged to present the project and to obtain permission and collaboration.

\footnotetext{
${ }^{1}$ Department of Health Sciences, University of Catanzaro "Magna Græcia", Catanzaro Italy; ${ }^{2}$ Addiction Department, Drug Addiction Service, U.O.C. SerT Soverato, Azienda Sanitaria Provinciale, Catanzaro Italy; ${ }^{3}$ Department of Pharmacy, Health and Nutritional Sciences, University of Calabria, Cosenza Italy. Correspondence: Aida Bianco (a.bianco@ unicz.it)

${ }^{4}$ At the time of this study he was with the Department of Health Sciences, University of Catanzaro "Magna Græcia", Catanzaro (Italy)

Received 3 August 2017; accepted 16 August 2017; advance online publication 27 September 2017. doi:10.1038/pr.2017.206
} 
Then, all students attending the third year (eighth grade) were invited to participate. During the hours of school attendance, a letter summarizing the purpose of the study and pointing out the voluntary and confidential nature of participation, an informed consent form to be delivered to the parents, and a questionnaire, was given to each selected student.

The questionnaire was developed based on the previous studies $(4,6)$, and was pretested for length and content on a sample of 30 potential respondents. The final survey was two pages in length, which was designed to be completed within $10 \mathrm{~min}$ and formulated into five sections: (1) sociodemographic characteristics (gender, age, residence, attended school, and class); (2) self-perceived mood (happy/normal, sad/depressed); (3) knowledge regarding alcohol policies (alcohol sales to minors, blood alcohol concentration limits for drivers, and so on); (4) attitudes toward alcohol drinking; and (5) behaviors regarding alcohol use (ever drunk alcohol in a lifetime, frequency of alcohol consumption, types of alcoholic beverages consumed, and parental drinking habits).

Alcohol consumption was also measured by asking how often (if ever) the student had drunk alcohol and the quantity per drinking occasion by asking the amount generally consumed each time. Respondents who reported drinking any beverage at least once (not for a special event) in the 30 days preceding the survey were classified as 'current drinkers' (12). A 'drink' was defined as a glass of wine, a can of beer, a shot of liquor, or a mixed drink. "Drunkenness" was defined as a transient condition following the administration of

Table 1. Selected characteristics of the study population

\begin{tabular}{|c|c|c|c|c|}
\hline \multirow[t]{2}{*}{ Characteristic } & \multicolumn{2}{|c|}{$\begin{array}{l}\text { Overall sample } \\
\qquad(n=1032)^{\mathrm{a}}\end{array}$} & \multicolumn{2}{|c|}{$\begin{array}{l}\text { Alcohol users } \\
(n=720)^{\mathrm{a}}\end{array}$} \\
\hline & $N$ & $\%$ & $N$ & $\%$ \\
\hline \multicolumn{5}{|l|}{ Gender } \\
\hline Male & 542 & 52.5 & 410 & 56.9 \\
\hline Female & 490 & 47.5 & 310 & 43.1 \\
\hline
\end{tabular}

Age, years

Mean \pm SD

$13.1 \pm 0.64$

$13.1 \pm 0.67$

Place of residence

Urban area

683

66.2

536

74.4

Rural area

349

$33.8 \quad 184$

25.6

Self-perceived daily mood

Happy/normal

768

75.4

494

69.9

Sad/depressed

250

24.6

213

\section{Parental alcohol use}

$\begin{array}{lllll}\text { No } & 295 & 29.2 & 114 & 16.2 \\ \text { Yes } & 716 & 70.8 & 591 & 83.8\end{array}$

\section{Knowledge about}

Minimum legal age to

$$
716
$$

purchase alcohol

Blood alcohol concentration limit for drivers alcohol or other psychoactive substances, resulting in disturbances in the level of consciousness, cognition, perception, effect or behavior, or other psychophysiological functions and responses (16). "Binge drinking" was defined as five or more alcoholic drinks on the same occasion $(5,6)$.

Each section elicited responses in two formats: closed-ended questions with multiple answers possible and yes or no questions. The questionnaire culminated with the option of providing additional comments. As a part of LdP program, the study protocol was approved by the Ethics Committee of the Local Health Authority of Reggio Emilia, Italy.

\section{Statistical Analysis}

Descriptive analyses were used to describe demographic characteristics and risk behaviors of participants, and to determine the prevalence of alcohol consumption. Data were summarized into frequencies and percentages. A multivariable backward stepwise logistic regression model was constructed to determine the explanatory variables independently related to a dichotomous measure of whether or not alcohol was used at least once in the lifetime. A model was developed according to the Hosmer and Lemeshow strategy (17), with the following steps: (1) univariate analysis of each variable considered, using the appropriate test statistic (chi-square test or $t$-test); (2) inclusion of any variable whose univariate test has a $P$-value $<0.25$; and (3) the results of the logistic regression analysis are presented as odds ratios (ORs ) and $95 \%$ confidence intervals (CIs ). A two-sided $P$-value for all tests of $<0.05$ was considered to be a statistically significant difference. The significance level for a variable's entry to the model was set at 0.2 and at 0.4 for removal.

The following explanatory variables were potentially included in the model: age (continuous), sex $($ male $=0$, female $=1$ ), place of residence (urban area $=0$, rural area $=1$ ), self-perceived daily mood (happy/normal $=0, \operatorname{sad} /$ depressed $=1$ ), parental alcohol use $($ no $=0$, yes $=1$ ), and attitudes toward alcohol use (agree with a belief that alcohol use is an unhealthy behavior $=0$, disagree with a belief that alcohol use is an unhealthy behavior $=1$ ), and correct knowledge about blood alcohol concentration limit for drivers $($ no $=0$, yes $=1$ ).

Stata version 14 statistical software package was used in conducting all data analyses (18).

\section{RESULTS}

A total of 1,032 participants with a mean age of 13.1 years (range 12-15 years), completed the survey for a response rate of $68 \%$. The main sociodemographic characteristics of the study population are shown in Table 1. Almost all students (98\%) said that alcohol can cause addiction, and 69.7\% knew the minimum legal age to purchase alcohol. Moreover, $88.5 \%$ of samples agreed that drinking alcohol is an unhealthy and risky behavior.

The respondents' alcohol use pattern is reported in Table 2. Almost $70 \%$ of the adolescents reported drinking alcohol at least once in their lifetime. Among alcohol users, the prevalence of current drinkers, that is, adolescents that had drunk on at least 1 day during the previous 30 days, was $16.7 \%$. About $10 \%$ of respondents reported drunkenness experience at least once in their lifetime and $2 \%$ reported binge drinking. The average number of drinks on a single occasion is 1.5 .

Beer is the most consumed alcoholic beverage (74\%). Furthermore, $20.7 \%$ reported hard liquor consumption. More than half of the eligible adolescents (59.4\%) reported alcohol use at home or at friends parties (46.8\%). 
Table 2. Patterns of alcohol use

\begin{tabular}{|c|c|c|}
\hline & $N$ & $\%$ \\
\hline Ever alcohol use $(1,032)$ & 720 & 69.8 \\
\hline \multicolumn{3}{|c|}{ Frequency of drinking in the previous 30 days (720) } \\
\hline Never & 600 & 83.3 \\
\hline$\geq 1$ time & 120 & 16.7 \\
\hline \multicolumn{3}{|c|}{ Number of drinks on a typical day when drinking (560) } \\
\hline 1 & 358 & 63.9 \\
\hline $2-3$ & 191 & 34.1 \\
\hline$\geq 4$ & 11 & 2 \\
\hline Ever experienced drunkenness (720) & 66 & 9.2 \\
\hline \multicolumn{3}{|l|}{ Kind of consumed beverages $(716)^{\mathrm{a}}$} \\
\hline Beer & 530 & 74 \\
\hline Wine & 338 & 47.2 \\
\hline Alcoholic aperitif & 153 & 21.4 \\
\hline Hard liquors & 148 & 20.7 \\
\hline \multicolumn{3}{|l|}{ Places where alcohol is consumed (716) ${ }^{\mathrm{a}}$} \\
\hline At home & 425 & 59.4 \\
\hline Friends' parties & 335 & 46.8 \\
\hline Bar/restaurant & 44 & 6.2 \\
\hline Other & 43 & 6 \\
\hline \multicolumn{3}{|l|}{ Reasons for alcohol consumption (206) } \\
\hline To become euphoric & 69 & 33.5 \\
\hline To get away from problems & 48 & 23.3 \\
\hline Because everyone else is doing it & 43 & 20.9 \\
\hline To feel more adult & 41 & 19.9 \\
\hline Other & 14 & 6.8 \\
\hline
\end{tabular}

${ }^{a}$ Multiple responses are allowed.

About 30\% of students reported drinking as a positive experience. The most frequently reported reasons for consuming alcohol were for celebrating or partying (33.5\%) and to get away from problems (23.3\%). Almost threequarters $(70.8 \%)$ of the overall sample said that their parents drink alcohol daily; among the adolescents who used alcohol, this percentage rises to $82.1 \%$.

At univariate analysis, alcohol use was significantly higher among older students $\left(t_{1,030}=-5.83, P<0.001\right)$, boys $\left(\chi^{2}=18.70, P<0.001\right)$, in those who lived in an urban area $\left(\chi^{2}=72.64, P<0.001\right)$, in those who did not know the correct alcohol concentration limit for drivers $\left(\chi^{2}=4.22, P=0.04\right)$, in those who reported a sad/depressed self-perceived mood $\left(\chi^{2}=38.74, P<0.001\right)$, who did not agree that drinking is an unhealthy behavior $\left(\chi^{2}=34.65, P<0.001\right)$, and in those who reported parental drinking habits $\left(\chi^{2}=190.75, P<0.001\right)$ (Table 3).
Table 3. Univariate and multivariate analyses of alcohol use according to various explanatory variables

\begin{tabular}{|c|c|c|c|c|}
\hline \multirow[t]{2}{*}{ Variable } & \multicolumn{2}{|c|}{ Univariate } & \multicolumn{2}{|c|}{$\begin{array}{c}\text { Multivariate } \\
\text { Log-likelihood }=-451.56 \\
X^{2}=319.3, P<0.001\end{array}$} \\
\hline & $N(720)^{a}$ & $\%$ & OR & $95 \% \mathrm{Cl}$ \\
\hline \multicolumn{5}{|l|}{ Gender } \\
\hline Male & 410 & 75.65 & $1.00^{\mathrm{b}}$ & \\
\hline \multirow[t]{2}{*}{ Female } & 310 & 63.27 & 0.58 & $0.41-0.80$ \\
\hline & \multicolumn{2}{|c|}{$\begin{array}{c}X^{2}=18.70,1 \mathrm{df}, \\
P<0.001\end{array}$} & & \\
\hline \multirow[t]{2}{*}{ Age, years (mean $\pm S D$ ) } & \multicolumn{2}{|c|}{$13.1 \pm 0.67$} & 1.88 & $1.37-2.56$ \\
\hline & \multicolumn{2}{|c|}{$\begin{array}{l}t=-5.83,1030 \\
\mathrm{df}, P<0.001\end{array}$} & & \\
\hline
\end{tabular}

Place of residence

Urban area

Rural area

$536 \quad 78.48$

$1.00^{\mathrm{b}}$

$184 \quad 52.72$

$0.29 \quad 0.21-0.40$

$X^{2}=72.64,1 \mathrm{df}$, $P<0.001$

Self-perceived daily mood

Happy/normal

Sad/depressed

$494 \quad 64.32$

$213 \quad 85.20$

$1.00^{\mathrm{b}}$

$X^{2}=38.74,1 \mathrm{df}$, $P<0.001$

Parental alcohol use

$\begin{array}{lrrrr}\text { No } & 114 & 38.64 & 1.00^{\mathrm{b}} & \\ \text { Yes } & 591 & 82.54 & 7.11 & 5.02-10.08 \\ & X^{2}=190.75,1 & & \\ & \text { df, } P<0.001 & & \end{array}$

Agree with the belief that alcohol use is an unhealthy behavior

$\begin{array}{lrrrr}\text { Yes } & 607 & 66.78 & 1.00^{\mathrm{b}} & \\ \text { No } & 110 & 93.22 & 2.43 & 1.11-5.31 \\ & X^{2}=34.65,1 \mathrm{df}, & & \\ P<0.001 & & \end{array}$

Correct knowledge about blood alcohol concentration limit for drivers

$\begin{array}{lrr}\text { No } & 411 \quad 72.23 \\ \text { Yes } & 286 \quad 66.20 \\ & \begin{array}{l}X^{2}=4.22, \\ P=0.04\end{array}\end{array}$

The total may not always sum to $\mathrm{N}$ because of missing data.

${ }^{b}$ Reference category.

${ }^{\mathrm{c}}$ Removed by the model. 


\section{Articles | zucco et al.}

The results of the multiple logistic regression analysis substantially confirmed the findings of the univariate analysis. Indeed, factors independently associated with the consumption of alcohol were being male (OR $0.58,95 \%$ CI $0.41-0.80$ ), being older (OR 1.88, 95\% CI 1.37-2.56), living in an urban area (OR $0.29,95 \%$ CI $0.21-0.40$ ), reporting a sad selfperceived mood (OR 2.76, 95\% CI 1.87-4.48), reporting parental drinking habits (OR 7.11, 95\% CI 5.02-10.08), and not considering alcohol use as an unhealthy behavior (OR 2.43, 95\% CI 1.11-5.31) (Table 3).

\section{DISCUSSION}

As far as we know, the present investigation is one of the few Italian studies aiming at evaluating alcohol consumption patterns among middle school students $(19,20)$, whereas most of the other studies have been focusing on young adults $(6,12)$. Moreover, the study provides useful information on factors influencing alcohol consumption in early adolescents.

Our results indicate high alcohol-drinking frequencies among younger adolescents, and confirm an extremely early contact with alcoholic beverages in Italy. These figures are similar to those reported in the literature. Indeed, our findings are comparable with the data for Italy emerging from the Health Behaviour in school-aged children (HBSC) 2010 survey, which indicated that $20.7 \%$ of 13 -year olds drink alcohol at least monthly (21). Similar data were also drawn from a recent European study, which reported that $73.4 \%$ of adolescents aged 10-13 years consumed alcoholic beverages at least once in their lifetime. However, this study shows a lower percentage of drunkenness experiences compared with our data $(3.7 \%$ vs. $9.2 \%)$ (14). The observations emerging from our study are extremely alarming, because of potential hazardous alcohol consumption patterns in adult life (10).

Alcohol use was associated with multiple factors that warrant careful attention. Male gender and an older age at the time of assessment were associated with alcohol use. These findings are consistent with the literature, suggesting that alcohol use increases with age throughout adolescence, and reaches its peak in males in late adolescence and early adulthood $(22,23)$. Moreover, as reported in previous studies (24), young people who live in an urban area are more likely to use alcohol. The place of residence may influence the drinking behaviors according to alcohol availability, norms for acceptable drinking behaviors, demographic characteristics, and economic factors. Obviously, adolescents with an urban residence may have more chance to purchase alcohol and to participate in social events or parties where alcohol is more likely to be available.

Another important finding from the present study is that parental drinking and lenient parental alcohols specific attitudes are positively associated with an adolescent's alcohol use. As reported in previous studies (25-27), parental alcohol use is directly associated with an adolescent's alcohol use as well. It is well known that family is the favored context for learning beliefs, patterns, and values that affect the broader regulatory social environment, and for this reason, it is considered a privileged context on which to intervene to reduce the adolescents' behavioral problems. Indeed, researchers have underlined the importance of parenttraining interventions for adolescents with alcohol use (27).

Consistent with prior research, our data analysis also showed that alcohol users felt significantly more depressed and were lacking self-assurance $(28,29)$. These results suggest that alcohol is often used as a self-medication or a coping strategy with stress or anxiety. Coping motives thus not only identify a reason or a potential trigger for drinking, but may also suggest a more uncontrolled style of drinking that is less responsive to social controls for drinking.

Furthermore, as expected, alcohol users in our study had a positive attitude toward alcohol use than other students and they did not agree that drinking is an unhealthy behavior (14). This finding suggests a low awareness or acceptance of the risks related to alcohol abuse, and highlights the need of correct prevention campaigns, especially addressed for young people. In this context, some interventions appear to be more effective, particularly those that are interactive, those based on the social influences approach, and those adopting a multimodal approach (30).

The results of our study should be interpreted in light of a few potential limitations. First of all, it should be noted that, since this study has a cross-sectional design, the relationship between the predictor variables and the dependent variables should not be taken as a cause-and-effect relationship; the study is able to only describe general associations. This study has a possible limitation regarding the method of collecting the information on alcohol consumption, as the data were obtained from a self-administered questionnaire. However, when the recall is restricted to a short period of time, and respondents are provided with anonymity and privacy and believe that the assessment is conducted for important reasons, the use of a self-reported method is valid for avoiding an unreliable recall of behavior (31).

Furthermore, our study involved only one Italian region. Although childhood development is generally consistent regardless of geography, there might be some differences in the substance use of our sample that may be due to cultural factors (32). However, our data are generally consistent with those generated by previous international lifestyle surveillance surveys conducted in our area on the same topics, and we are confident that the findings of the study may be representative of the Southern regions.

\section{CONCLUSION}

Our results suggest that alcohol use among early adolescence is widespread. Multicomponent interventions are required in order to minimize and reduce the average levels of alcohol drinking among early and mid-adolescents. Prevention programs should therefore focus particularly on the years of transition from primary to secondary school in an effort to delay the onset of alcohol use. 


\section{STATEMENT OF FINANCIAL SUPPORT}

This research did not receive any specific grant from funding agencies in the public, commercial, or not-for-profit sectors.

Disclosure: The authors declare no conflict of interest.

\section{REFERENCES}

1. Curtis AC. Defining adolescence. J Adolesc Family Health 2015;7 article 2.

2. Balocchini E, Chiamenti G, Lamborghini A. Adolescents: which risks for their life and health? J Prev Med Hyg 2013;54:191-4.

3. Marshall EJ. Adolescent alcohol use: risks and consequences. Alcohol Alcohol 2014;49:160-4.

4. Kann L, Kinchen S, Shanklin SL, et al. Youth risk behavior surveillanceUnited States, 2013. MMWR 2014;63:1-168.

5. Hibell B, Guttormsson U, Ahlström S, et al. The 2011 ESPAD Report. Substance Use Among Students in 36 European Countries. ESPAD (http://www.can.se/contentassets/8d8cb78bbd28493b9030c65c598e3301/ the_2011_espad_report_full.pdf.) Accessed 03 September 2016.

6. Flotta D, Micò R, Nobile CG, et al. Consumption of energy drinks, alcohol, and alcohol-mixed energy drinks among Italian adolescents. Alcohol Clin Exp Res 2014;38:1654-61.

7. Istat. L'uso e l'abuso di alcol in Italia. Anno 2014 (http://www.istat.it/it/ archivio/156223 Accessed 01 August 2016.

8. Welch KA, Carson A, Lawrie SM. Brain structure in adolescents and young adults with alcohol problems: systematic review of imaging studies. Alcohol Alcohol 2013;48:433-44.

9. Hanson KL, Medina KL, Padula CB, et al. Impact of adolescent alcohol and drug use on neuropsychological functioning in young adulthood: 10year outcomes. J Child Adolesc Subst Abuse 2011;20:135-54.

10. McCambridge J, McAlaney J, Rowe R. Adult consequences of late adolescent alcohol consumption: a systematic review of cohort studies. PLoS Med 2011;8:e1000413.

11. Calvert WJ, Bucholz KK, Steger-May K. Early drinking and its association with adolescents' participation in risky behaviors. J Am Psychiatr Nurses Assoc 2010;16:239-51.

12. Nobile CG, Trani F, Di Stasio SM, Angelillo IF. Cigarette smoking and alcohol behaviour among adolescents in Italy. Public Health 2006;120:942-5.

13. Grenard JL, Dent CW, Stacy AW. Exposure to alcohol advertisements and teenage alcohol-related problems. Pediatrics 2013;131:369-79.

14. Bailly D, Rouchaud A, Garcia C, et al. Alcohol use in young adolescents. A survey in French secondary schools. Arch Pediatr 2015;22:510-7.

15. Allara E, Angelini P, Gorini G, et al. A prevention program for multiple health-compromising behaviors in adolescence: baseline results from a cluster randomized controlled trial. Prev Med 2015;71:20-6.

16. World Health Organization Management of substance abuse (http:// http://www.who.int/substance_abuse/terminology/acute_intox/en/) Accessed 01 August 2016.
17. Hosmer DW, Lemeshow S. Applied Logistic Regression, 2nd edn. New York: Wiley and Sons, 2000.

18. Stata Corporation: Stata Reference Manual. Release 14, College Station, TX: StataCorp LP, 2009.

19. Agabio R, Mereu A, Contu P, Gessa GL. Unawareness of alcoholic content of alcopops among 13-year old Italian teenagers. Alcoholism Drug Depend 2013;2:1.

20. Innamorati M, Maniglio R. Psychosocial correlates of alcohol use and heavy episodic drinking among italian adolescents: data from the second international self-reported delinquency study. Am J Addict 2015;24: 507-14.

21. Cavallo F, Giacchi M, Vieno A Rome Ist Sup. Sanit, 2013. Studio HBSCItalia (Health Behaviour in School-Aged Children): rapporto sui dati. Rapporti ISTISAN, No. 13/5, pp. 1-128, 2010.

22. Donovan JE. Adolescent alcohol initiation: a review of psychosocial risk factors. J Adolesc Health 2004;35:529e7-e18.

23. Schulte MT, Ramo D, Brown SA. Gender differences in factors influencing alcohol use and drinking progression among adolescents. Clin Psychol Rev 2009;29:535-47.

24. Dixon MA, Chartier KG. Alcohol use patterns among urban and rural residents: demographic and social influences. Alcohol Res 2016;38: 69-77.

25. Van Damme J, Maes L, Kuntsche E, et al. The influence of parental drinking on offspring's drinking motives and drinking: a mediation analysis on 9 year follow-up data. Drug Alcohol Depend 2015;149:63-70.

26. Mares SH, van der Vorst H, Engels RC, Lichtwarck-Aschoff A. University parental alcohol use, alcohol-related problems, and alcohol-specific attitudes, alcohol-specific communication, and adolescent excessive alcohol use and alcohol-related problems: an indirect path model. Addict Behav 2011;36:209-16.

27. Pellerone M, Tolini G, Polopoli C. Parenting, identity development, internalizing symptoms, and alcohol use: a cross-sectional study in a group of Italian adolescents. Neuropsychiatr Dis Treat 2016;12:1769-78.

28. Chung T, Martin CS. What were they thinking? Adolescents' interpretations of DSM-IV alcohol dependence symptom queries and implications for diagnostic validity. Drug Alcohol Depend 2005;80:191-200.

29. Chung T, Martin CS, Winters KC. Diagnosis, course, and assessment of alcohol abuse and dependence in adolescents. Recent Dev Alcohol 2005;17:5-27.

30. Gorini G, Carreras G, Bosi S, et al. Effectiveness of a school-based multicomponent smoking prevention intervention: the LdP cluster randomized controlled trial. Prev Med 2014;61:6-13.

31. Althubaiti A. Information bias in health research: definition, pitfalls, and adjustment methods. J Multidiscip Healthc 2016;9:211-7.

32. Kokkevi A, Richardson C, Florescu S, et al. Psychosocial correlates of substance use in adolescence: a cross-national study in six European countries. Drug Alcohol Depend 2007;86:67-74. 